\title{
Neurites containing the neurofilament-triplet proteins are selectively vulnerable to cytoskeletal pathology in Alzheimer's disease and transgenic mouse models
}

\author{
Stanislaw Mitew ${ }^{1,2}$, Matthew T. K. Kirkcaldie ${ }^{1,2}$, Tracey C. Dickson ${ }^{3}$ and James C. Vickers ${ }^{1,2 *}$ \\ ${ }^{1}$ Wicking Dementia Research and Education Centre, University of Tasmania, Hobart, TAS, Australia \\ ${ }^{2}$ School of Medicine, University of Tasmania, Hobart, TAS, Australia \\ ${ }^{3}$ Menzies Research Institute, University of Tasmania, Hobart, TAS, Australia
}

Edited by:

Patrick R. Hof, Mount Sinai School of

Medicine, USA

Reviewed by:

Stephen D. Ginsberg, Nathan Kline Institute, USA

Gregory Elder, The Mount Sinai

Medical Center, USA

${ }^{*}$ Correspondence:

James C. Vickers, Wicking Dementia Research and Education Centre,

University of Tasmania, Private Bag

34, Hobart, TAS 7000, Australia

e-mail: james.vickers@utas.edu.au
Amyloid- $\beta$ plaque accumulation in Alzheimer's disease (AD) is associated with dystrophic neurite (DN) formation and synapse loss in principal neurons, but interneuron pathology is less clearly characterized. We compared the responses of neuronal processes immunoreactive for either neurofilament triplet $\left(\mathrm{NF}^{+}\right)$or calretinin $\left(\mathrm{CR}^{+}\right)$to fibrillar amyloid $(\mathrm{A} \beta)$ plaques in human end-stage and preclinical AD, as well as in APP/PS1 and Tg2576 transgenic mouse $A D$ models. Neurites traversing the $A \beta$ plaque core, edge, or periphery, defined as 50,100 , and $150 \%$ of the plaque diameter, respectively, in human $A D$ and transgenic mouse tissue were compared to age-matched human and wild-type mouse controls. The proportion of $\mathrm{NF}^{+}$neurites exhibiting dystrophic morphology (DN) was significantly larger than the proportion of dystrophic $\mathrm{CR}^{+}$neurites in both human $\mathrm{AD}$ and transgenic mice $(p<0.01)$. Additionally, the number of $\mathrm{NF}^{+}$, but not $\mathrm{CR}^{+}, \mathrm{DNs}$, correlated with $\mathrm{A} \beta$ plaque size. We conclude that $\mathrm{CR}^{+}$interneurons appear to be more resistant than $\mathrm{NF}^{+}$neurons to AD-mediated cytoskeletal pathology.

\section{Keywords: neurofilament triplet, interneuron, dystrophic neurites, amyloid plaque, Alzheimer's disease}

\section{INTRODUCTION}

Alzheimer's disease (AD) is commonly associated with a cascade of neuronal cytoskeletal alterations - neurofibrillary tangles (NFTs), neuropil threads and dystrophic neurite (DN) formation, causing spine and synapse loss - as well as overt neuronal degeneration (Spires et al., 2005; Adalbert et al., 2009; Vickers et al., 2009). These pathological changes develop in a characteristic spatiotemporal progression across the cortex in most human cases (Braak et al., 2011), and to some extent in AD mouse models (Blanchard et al., 2003), suggesting a differential subregional and cellular susceptibility to $\mathrm{AD}$. DNs are intimately associated with extracellular depositions of amyloid $\beta(\mathrm{A} \beta)$, known as plaques (Dickson et al., 1999; Woodhouse et al., 2009b) and present as swollen tortuous neurites $10-60 \mu \mathrm{m}$ in diameter, with variable morphology and composition depending on the pathological stage of $\mathrm{AD}$ (Vickers et al., 1996; Su et al., 1998; Woodhouse et al., 2009b). In preclinical $\mathrm{AD}$ cases and transgenic mice, $\mathrm{A} \beta$ plaque-associated $\mathrm{DNs}$ are predominantly labeled with antibodies to neurofilament triplet proteins (NFs) and $\alpha$-internexin, whereas in end-stage $\mathrm{AD}$, subgroups of DNs contain NFs, abnormal tau protein, or a rim of NFs around a tau core (Benzing et al., 1993; Su et al., 1996; Dickson et al., 1999, 2005). This suggests that DN composition may shift from NF/ $\alpha$-internexin to predominantly tau, as disease progresses (Blanchard et al., 2003; Vickers et al., 2009). This progression may imply similar shifts elsewhere in affected neurons.

Neurofilament triplet proteins belong to the type IV intermediate filament protein family, and, in the neocortex of many mammalian species, are predominantly expressed by a pyramidal subpopulation in layers $2-6$ making corticocortical connections (Vickers and Costa, 1992; Hof etal., 1995; Van der Gucht etal., 2007; Paulussen etal., 2011). The NF "triplet" refers to three genetically and structurally interrelated subunits [68 kDa (NF-L), $160 \mathrm{kDa}(\mathrm{NF}-\mathrm{M})$, and $200 \mathrm{kDa}$ (NF$\mathrm{H})$ ] that are typically co-expressed, and which co-polymerize to form intermediate filaments (Szaro and Strong, 2010). In the rat neocortex, NF-immunopositive $\left(\mathrm{NF}^{+}\right)$neurons account for approximately $10-13 \%$ of all neurons (Kirkcaldie et al., 2002), whereas $20-30 \%$ of human temporal cortex neurons are $\mathrm{NF}^{+}$ (Hof et al., 1990).

The effect of $\mathrm{AD}$ on $\mathrm{NF}^{+}$neuronal populations has been widely studied as a possible insight to the basis of neuronal vulnerability, and perhaps the pathological mechanisms of AD. SMI32, an antibody which recognizes dephosphorylated epitopes of the NF$\mathrm{M}$ and NF-H subunits but does not cross-react with tau, labels a subset of layer 2, 3, and 5 pyramidal neurons which may be particularly susceptible to neurofibrillary pathology (Lewis et al., 1987; Morrison et al., 1987; Hof and Morrison, 1990; Hof et al., 1990, 1995; Mann, 1996). $\mathrm{NF}^{+}$neurons in superior frontal and inferior medial temporal association cortices (Hof et al., 1990), primary and secondary visual cortex (Hof and Morrison, 1990), and hippocampal and entorhinal regions (Vickers et al., 1992, 1994) show a high degree of vulnerability to NFT formation and degeneration. Interestingly, cortical neurons that lack the NFtriplet, including most inhibitory interneurons, do not develop NFTs and show a much lower susceptibility to degeneration in AD (Hof et al., 1991, 1993; Fonseca and Soriano, 1995; Sampson et al., 1997). Conversely, those subpopulations of inhibitory neurons which do express the NF-triplet are more likely to develop 
NFTs in AD (Hof etal., 1993; Sampson et al., 1997; Leuba et al., 1998).

To further examine if $\mathrm{NF}^{+}$neurons and their processes are selectively vulnerable to $\mathrm{AD}$ pathology, we performed a morphological analysis of neurites in early and end-stage $\mathrm{AD}$ cases, as well as in two widely used transgenic mouse models, APP/PS1 and $\mathrm{Tg} 2576$, that develop $\mathrm{AD}$-like $\mathrm{A} \beta$ plaque pathology. We also analyzed calretinin-immunopositive $\left(\mathrm{CR}^{+}\right)$neurites as a non-neurofilament comparison: although a small population of Cajal-Retzius cells in layer 1 are both $\mathrm{CR}^{+}$and $\mathrm{NF}^{+}$(Fonseca and Soriano, 1995), $\mathrm{CR}^{+}$interneurons in the layers we studied are from $\mathrm{NF}^{-}$neurons (del Rio and DeFelipe, 1997; Sampson et al., 1997).

\section{MATERIALS AND METHODS HUMAN TISSUE}

Human brain tissue was acquired from the Sun Health Research Institute (AZ, USA) and the National Health and Medical Research Council Brain Bank (Adelaide, Australia), meeting all necessary ethical approvals as previously described (Dickson et al., 1999; Woodhouse et al., 2009b). Blocks of inferior temporal cortex, a major site of $\mathrm{A} \beta$ deposition (Braak et al., 2011), were immersionfixed with either $10 \%$ formalin or $4 \%$ paraformaldehyde. Human tissue comprised six sporadic $\mathrm{AD}$ cases meeting CERAD diagnostic criteria ("end-stage" AD; Braak stage IV-V), six non-demented cases with neocortical plaque pathology but no NFTs (i.e., Braak stage III), termed "preclinical" AD (Price et al., 2009), and five age-matched non-demented cases lacking cortical $\mathrm{A} \beta$ plaques or neurofibrillary pathology (Table 1).

\section{MOUSE TISSUE}

All mouse procedures were approved by the Animal Ethics Committee of the University of Tasmania and are in accordance with the Australian Code of Practice for the Care and Use of Animals for Scientific Purposes. Briefly, 12-month-old Tg2576 $\left(\right.$ APP $_{\text {Swe670/671; }}$ Hsiao et al., 1996), APP/PS1 (APP Swe $_{\text {PSEN1dE9; }}$ Jankowsky et al., 2004), and age-matched C57BL/6 wild-type mice ( $n=5$, for each group) were terminally anesthetized (sodium pentobarbitone, $140 \mathrm{mg} / \mathrm{kg}$, i.p.), transcardially perfused $(0.01 \mathrm{M}$ phosphate-buffered saline, PBS, then $4 \%$ paraformaldehyde in PBS). Brains were post-fixed for $2 \mathrm{~h}$ at $4^{\circ} \mathrm{C}$, before serial $40 \mu \mathrm{m}$ coronal sections were cut on a vibratome from bregma -1.00 to $-2.50 \mathrm{~mm}$ (Franklin and Paxinos, 2008) and immunolabeled as outlined below. Regions corresponding to the primary somatosensory cortex were analyzed.

\section{IMMUNOHISTOCHEMISTRY}

All immunohistochemical procedures were performed identically. Sections were blocked for $2 \mathrm{~h}$ in $10 \%$ goat serum and $0.3 \%$ Triton-X (both Sigma-Aldrich) by volume in $0.01 \mathrm{M}$ PBS at room temperature, followed by overnight incubation with primary antibodies in blocking solution at $4^{\circ} \mathrm{C}$. Human and mouse cortical sections were co-immunolabeled with rabbit anti-CR (1:2000, Millipore) and a cocktail of mouse SMI32 (de-phosphorylated NF) and SMI312 (phosphorylated NF; both at 1:2000, Covance) to visualize $\mathrm{CR}^{+}$and $\mathrm{NF}^{+}$subpopulations of interneurons and principal neurons, respectively. Sections were then counter-stained with $0.0125 \%$ thioflavin-S (Sigma-Aldrich) and $40 \%$ ethanol in $0.01 \mathrm{M}$ PBS, to visualize fibrillar A $\beta$ plaques. Species-appropriate

Table 1 | Human brain cases utilized for immunohistochemistry and analysis.



*SHRI, Sun Health Research Institute (AZ, USA); NTRC, National Tissue Resource Centre (Melbourne, Australia); U Syd, Department of Pathology, University of Sydney (Australia). 
Alexa 488 and 594 conjugated secondary antibodies (1:500, Molecular Probes) were applied for $2 \mathrm{~h}$ at room temperature, followed by extensive washes and mounting with PermaFluor mounting medium (Thermo Fisher Scientific).

\section{ANALYSIS OF NEURITE SUSCEPTIBILITY}

For both $\mathrm{AD}$ and mouse cortex, three sections per individual were used, in each of which 10 plaques were chosen (30 plaques per case/animal) to assess their effects on $\mathrm{CR}^{+}$and $\mathrm{NF}^{-}$neurites. Plaques were chosen at random in layers 2-4, which contain the majority of $\mathrm{CR}^{+}$interneuron perikarya and processes in humans (Fonseca and Soriano, 1995; del Rio and DeFelipe, 1997) and mice (Park et al., 2002), as well as the highest plaque load (Braak and Braak, 1991). Using previously described criteria for pathological cytoskeletal alterations, labeled neurites with focal increases in diameter, such as swellings, highly undulating trajectories or with a change in course greater than $90^{\circ}$ from the original trajectory, were counted as "dystrophic" (Vickers et al., 1996; Dickson et al., 1999; Knowles et al., 1999; Le et al., 2001; Figures 1A,B). Labeled neurites that did not meet any of the dystrophic criteria were considered normal. For each plaque, the number of $\mathrm{CR}^{+}$and $\mathrm{NF}^{+}$neurites traversing the core, edge, and periphery (defined as 50, 100, and $150 \%$ of plaque diameter, respectively; Figures 1C,D) was determined to assess whether these zones differed in neuropil damage. More than 3000 intact and DNs per case type were counted. The average plaque area for human $\mathrm{AD}$ $\left(1290 \pm 101 \mu \mathrm{m}^{2}\right)$ or transgenic mice $\left(1070 \pm 67 \mu \mathrm{m}^{2}\right)$ was used

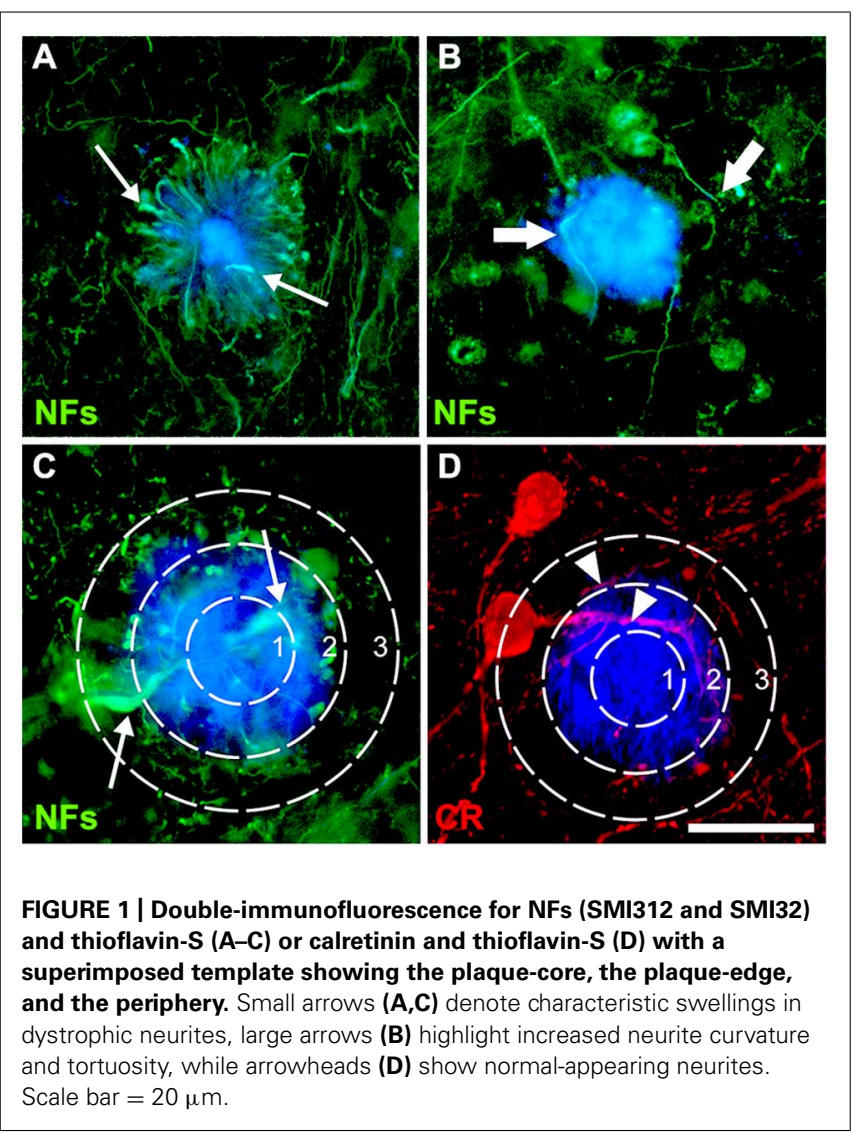

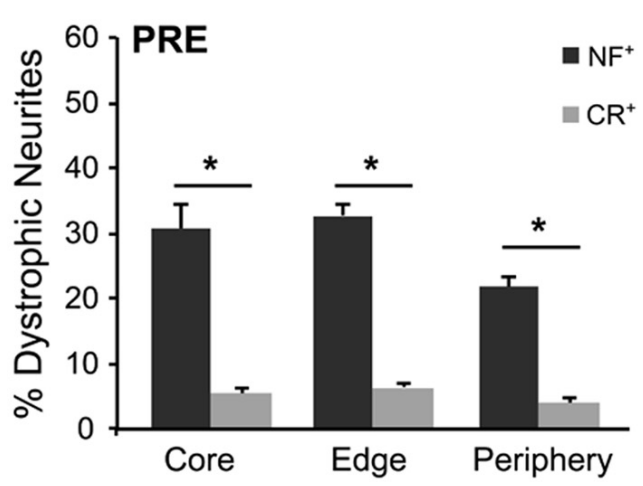
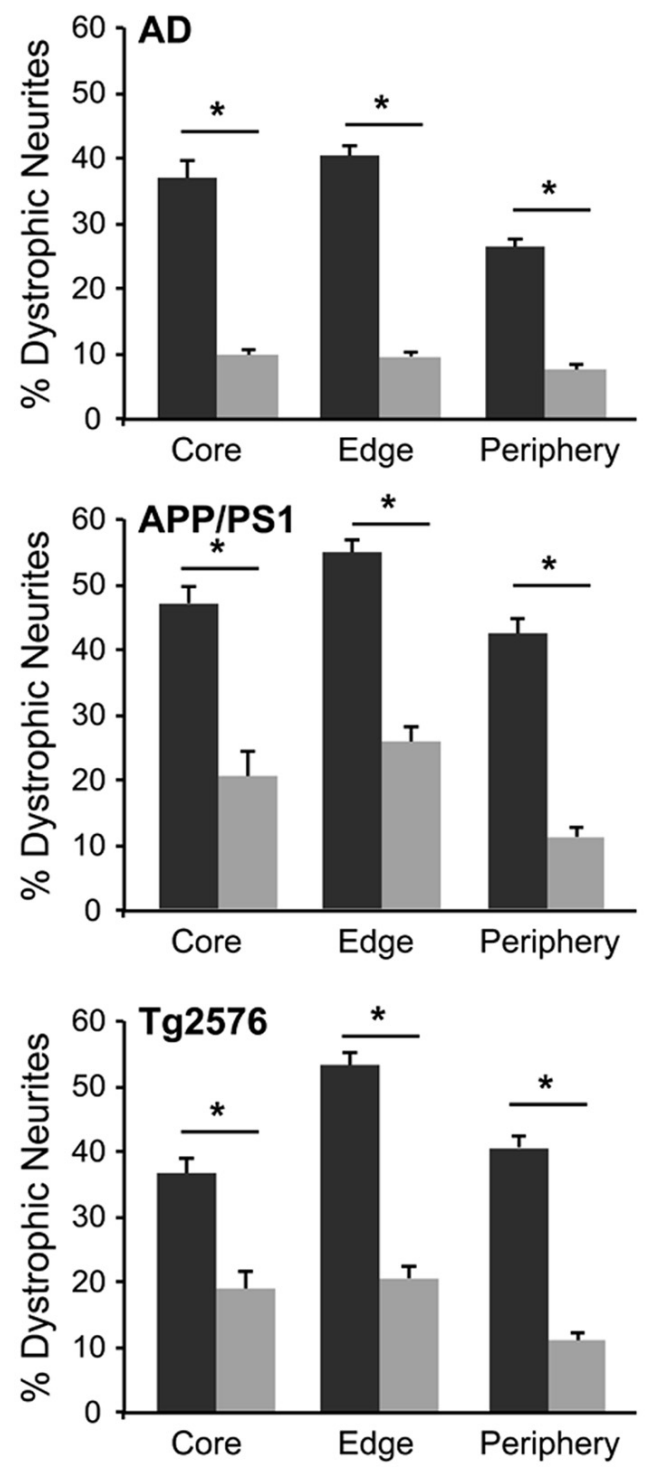

FIGURE 2 | Graphs illustrating the percentage of NF- (gray bars) and CR- (white bars) immunolabeled dystrophic neurites associated with fibrillar $A \beta$ plaques at the three zones in AD, preclinical AD, APP/PS1, and Tg2576 transgenic mice, respectively ( \pm SEM). There are significantly more dystrophic $\mathrm{NF}^{+}$neurites traversing the $\mathrm{A} \beta$ plaque core, edge, and periphery than $\mathrm{CR}^{+}$dystrophic neurites within all case types $\left(^{*} p<0.05\right.$, t-test). 

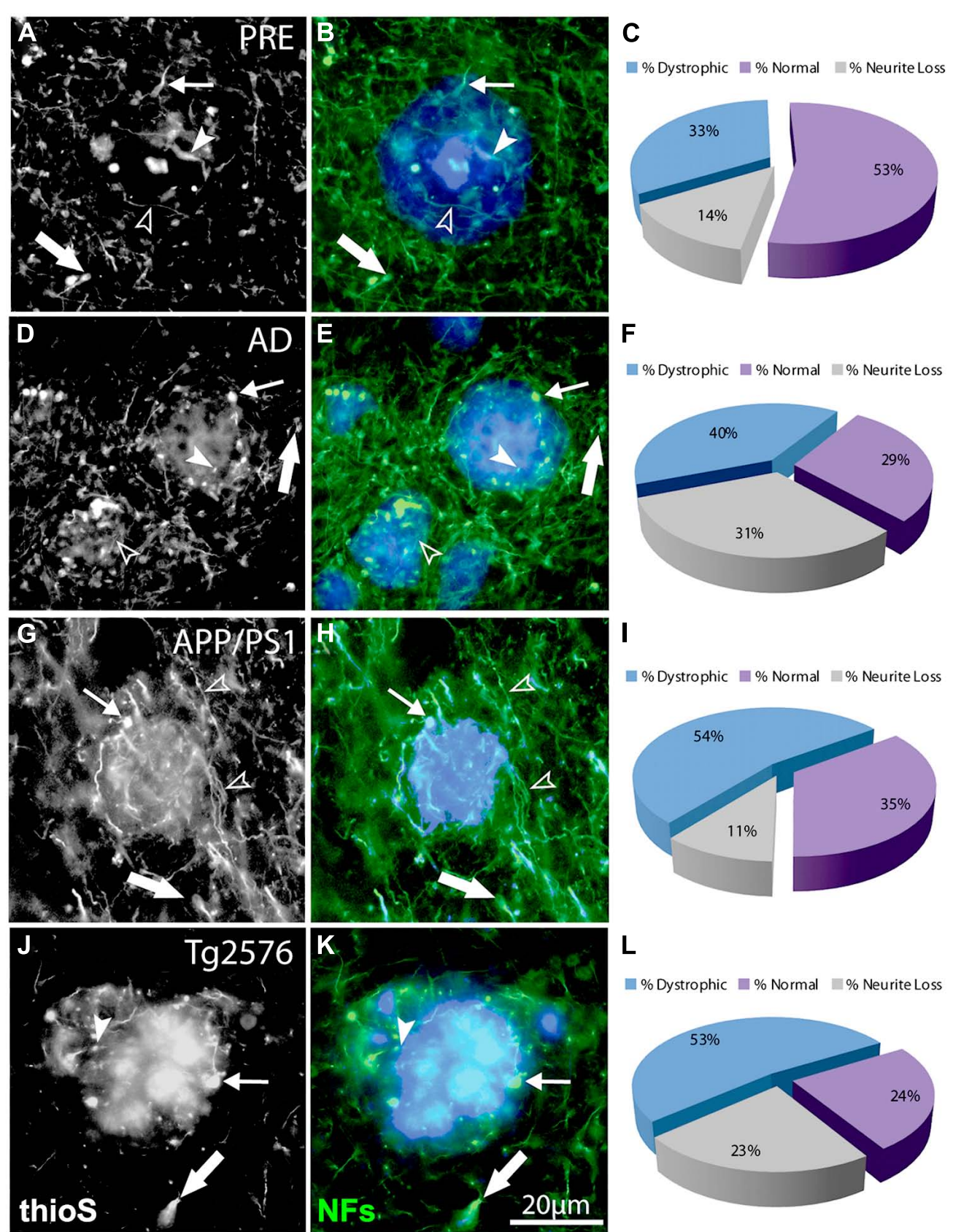

FIGURE 3 | Double-immunofluorescence labeling of representative thioflavin-S plaques and $\mathrm{NF}^{+}$neurites from preclinical $A D(A, B)$, end-stage $A D(D, E), A P P / P S 1(G, H)$, and Tg2576 $(J, K)$ transgenic mice shows classical bulb-like swellings containing neurofilaments indicated by filled arrowheads in the plaque-core, small arrows at the plaque edge, and large arrows in the periphery. Normal-appearing neurites in association with thioflavin-S labeled fibrillar plaques are indicated by unfilled arrowheads. A large proportion of $\mathrm{NF}^{+}$neurites associated with $\mathrm{A} \beta$ plaques are dystrophic (blue fraction: $\mathbf{C , F}, \mathbf{I}, \mathbf{L}$ ) and there is extensive neruite loss in end-stage $A D$ and Tg2576 mice (gray fraction: $\mathbf{F}, \mathbf{L}$ ). to define plaque-equivalent areas placed randomly in images of control tissue using the grid function in ImageJ, to estimate normal neurite density in these regions. The number of neurites per plaque was normalized to the mean plaque diameter for each case, to allow comparisons of proportions between zones. The mean number of dystrophic and normal neurites in each plaque zone (core, edge, or periphery) was expressed as a percentage of the mean control neurite number. Neurite density loss in AD and transgenic tissue relative to control values was calculated as a percentage: $100 \times[1-$ (total normal and $\mathrm{DNs}) /($ total neurites in plaque-equivalent control areas)].

To quantify plaque load, five randomly selected sections of inferior temporal gyrus (ITG) neocortex from pia to the white matter were collected for each end-stage $\mathrm{AD}$ and preclinical $\mathrm{AD}$ case, 

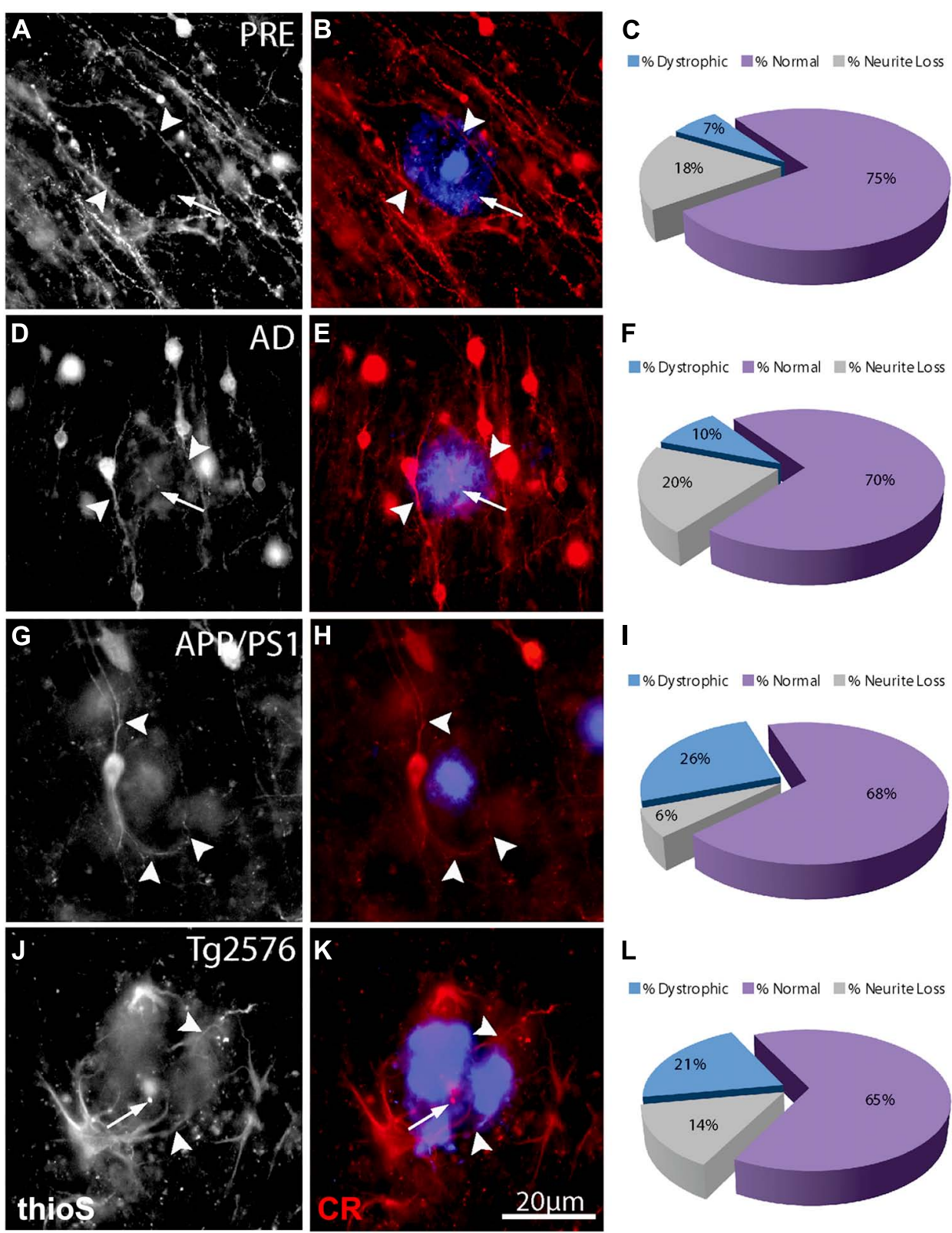

FIGURE 4 | Double-immunofluorescence labeling of representative thioflavin-S plaques and $C R^{+}$neurites from preclinical $A D(A, B)$, end-stage AD (D,E), APP/PS1 (G,H), and Tg2576 (J,K) transgenic mice shows a relative paucity of swellings containing calretinin (arrows). Filled arrowheads indicate normal-appearing CR neurites in association with thioflavin-S labeled fibrillar plaques. In most cases, these neurites appear to elaborate around plaques. A large proportion of CR-ir neurites associated with $A \beta$ plaques are normal (purple fraction: $\mathbf{C}, \mathbf{F}, \mathbf{I}, \mathbf{L}$ ) in all case types and there are comparatively fewer dystrophic neurites (blue fraction: C,F,I,L). and an area approximately $1200 \mu \mathrm{m}$ wide was analyzed in each, as previously described (Woodhouse et al., 2009a). The percentage area that was stained by thioflavin- $S$ was then calculated in ImageJ.

\section{IMAGE ACQUISITION}

Images were captured using a Leica DM LB2 epifluorescence microscope with a cooled CCD Magnafire (Optronics) camera or on a Zeiss LSM510 confocal microscope equipped with Zen software and Ar 488, HeNe 543 lasers. All image analysis was performed using NIH ImageJ (version 1.45p) software.

\section{STATISTICAL ANALYSIS}

Statistical analyses for comparisons of group means was conducted by one-way analysis of variance (ANOVA) followed by Dunnett's post hoc tests or unpaired $t$-tests as appropriate using GraphPad Prism software (version 5.0b) with $p<0.05$ (CI 95\%) considered significant. In some cases, a Pearson product-moment correlation 
was computed to assess the relationship between DN numbers and mean plaque size. Mean values were reported \pm standard error of the mean (SEM).

\section{RESULTS}

CALRETININ-IMMUNOPOSITIVE INTERNEURONS ASSOCIATED WITH A $\beta$ PLAQUES ARE MORE RESISTANT TO NEURITIC PATHOLOGY THAN NEUROFILAMENT-IMMUNOREACTIVE NEURONS

A cocktail comprising SMI32 and SMI312 antibodies was used to label the $\mathrm{NF}^{+}$subpopulation of neurites, which we assume are chiefly derived from pyramidal cells of cortical layers 2-6 (Van der Gucht etal., 2007; Paulussen etal., 2011). Although neurites from a subset of basket cells, or projecting fibers from subcortical and subthalamic regions, would also be $\mathrm{NF}^{+}$(Hof and Morrison, 1990; Hof et al., 1990), their fewer numbers and less extensive neurite fields indicates that pyramidal neurites make up the majority of $\mathrm{NF}^{+}$processes examined in cortical layers 2-4 (Hof et al., 1995).

The number of $\mathrm{NF}^{+}$and $\mathrm{CR}^{+}$neurites scored as "dystrophic" or "normal" were analyzed at 50,100, and $150 \%$ of $A \beta$ plaque diameters (core, edge, and periphery, respectively) and mean values were expressed as percentages of mean human and mouse control values. For all case types analyzed, the percentage of dystrophic $\mathrm{NF}^{+}$neurites was significantly higher than $\mathrm{CR}^{+}$neurites (Figure 2, $p<0.01, t$-test). Of the three zones examined, $\mathrm{NF}^{+}$ DNs were most common at the plaque edge in APP/PS1 mice $(54.6 \pm 2.2 \%)$ followed by $\mathrm{Tg} 2576$ mice $(53.2 \pm 2.0 \%)$, endstage $\mathrm{AD}(40.3 \pm 1.7 \%)$, and preclinical $\mathrm{AD}$ cases $(33.4 \pm 1.9 \%$; mean \pm SEM). Similarly, $\mathrm{CR}^{+} \mathrm{DNs}$ were most prevalent at the plaque edge in APP/PS1 (25.6 $\pm 2.5 \%), \operatorname{Tg} 2576$ (20.5 $\pm 1.7 \%)$, end-stage $(9.6 \pm 0.8 \%)$, and preclinical $(6.7 \pm 0.7 \%) \mathrm{AD}$ cases. The greatest difference between $\mathrm{NF}^{+}$and $\mathrm{CR}^{+}$neurite responses in all tissue types was in the plaque periphery, where the proportion of DNs was, on average, four times greater for $\mathrm{NF}^{+}$neurites compared to $\mathrm{CR}^{+}$(Figures 2-4). Representative immunolabeled sections demonstrate much greater dystrophy in $\mathrm{NF}^{+}$neurites (Figure 3) than in $\mathrm{CR}^{+}$neurites (Figure 4).

We also counted normal neurites around $\mathrm{A} \beta$ fibrillar deposits and in control tissue, to estimate absolute neurite loss. Both $\mathrm{NF}^{+}$ (Figure 5A) and $\mathrm{CR}^{+}$(Figure 5B) neurites exhibited comparable pronounced neurite density loss in the plaque core in end-stage $\mathrm{AD}$, preclinical AD, APP/PS1, and Tg2576 cases $(p<0.01$, oneway ANOVA, Dunnett's post hoc tests). However, no significant loss of $\mathrm{CR}^{+}$neurites occurred at the plaque edge or periphery ( $p>0.05$ in all cases), whereas $\mathrm{NF}^{+}$neurites showed significant losses in all zones excepting plaque periphery in preclinical AD. Furthermore, in all four case types, the proportion of normal $\mathrm{CR}^{+}$ neurites at the plaque edge (Figures 4C,F,I,L) was significantly higher than for $\mathrm{NF}^{+}$neurites (Figures 3C,F,I,L; $p<0.01, t$-test). Interestingly, many normal $\mathrm{CR}^{+}$neurites in the periphery had elaborated processes around $A \beta$ plaques, instead of traversing the plaque or stopping at the plaque border as $\mathrm{NF}^{+}$neurites often did (arrowheads, Figure 4).

\section{THE NUMBER OF NF-ir DNs IS DEPENDENT ON A $\beta$ PLAQUE SIZE}

The mean $A \beta$ plaque size was determined in all case types, with the largest plaques occurring in end-stage $\mathrm{AD}\left(1290 \pm 101 \mu \mathrm{m}^{2}\right)$ and


FIGURE 5 | Graphs showing the percentage neurite density loss for $\mathbf{N F}^{+}(\mathbf{A})$ and $\mathbf{C R}^{+}(\mathbf{B})$ neurites. There is a significant $\mathrm{NF}^{+}$neurite density loss for the different case types across all three regions $\left(\mathbf{A},{ }^{*} p<0.01\right.$, ANOVA with Dunnett's post hoc test), whereas $\mathrm{CR}^{+}$neurite density loss for the different case types was significant only in the plaque-core (B, $\left.{ }^{*} p<0.01\right)$. Error bars denote standard error of the mean.

the smallest in preclinical $\mathrm{AD}\left(870 \pm 93 \mu \mathrm{m}^{2}\right)$. In human cases, the mean number of dystrophic $\mathrm{NF}^{+}$neurites correlated with $\mathrm{A} \beta$ plaque size in both preclinical (Figure 6A, $r=0.46, p<0.001$, $t$-test) and end-stage $\mathrm{AD}$ (Figure 6B, $r=0.82, p<0.001, t$-test) cases. There was a similar pattern in the transgenic mice, with higher numbers of $\mathrm{NF}^{+} \mathrm{DNs}$ associated with larger plaques in APP/PS1 (Figure 6C, $r=0.72, p<0.001, t$-test; mean plaque size $=1072 \pm 67 \mu^{2}$ ) and Tg2576 (Figure 6D, $r=0.39$, $p<0.01, t$-test; mean plaque size $\left.=882 \pm 118 \mu \mathrm{m}^{2}\right)$ animals. In contrast, $\mathrm{CR}^{+} \mathrm{DN}$ counts did not correlate significantly with plaque size in any of the groups $(p>0.05$ for all). Furthermore, in human end-stage cases, the total number of $\mathrm{NF}^{+}$ DNs per case correlated with thioflavin-S plaque load (Figure $6 \mathrm{~F}$, $r=0.89, p<0.05)$, but not in preclinical AD cases $(r=0.17$, $p=0.12)$.

\section{DISCUSSION}

Human $\mathrm{AD}$ is characterized by the accumulation of extracellular $\mathrm{A} \beta$ plaques and intracellular NFTs comprised chiefly of hyperphosphorylated tau (Braak and Braak, 1991; Braak et al., 2011). Interestingly, $\mathrm{NF}^{+}$neurons may be especially vulnerable 


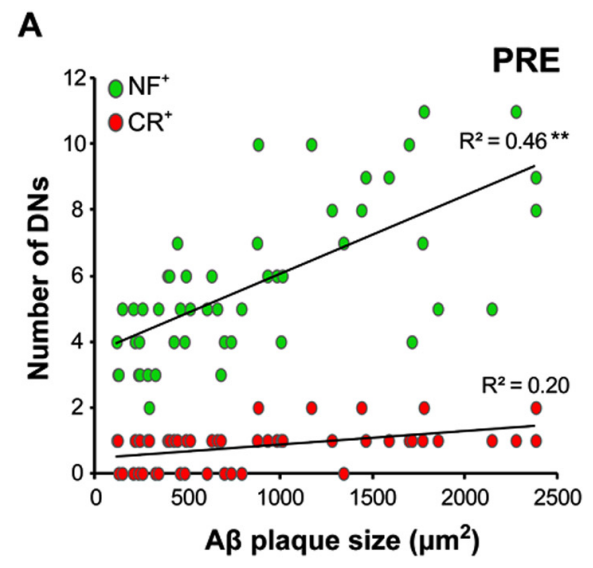

C

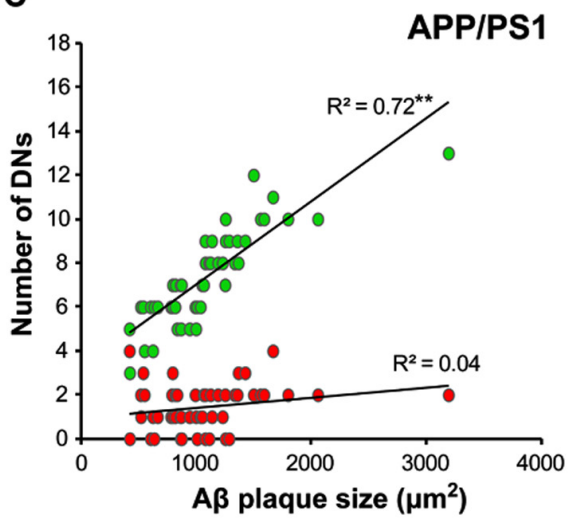

E

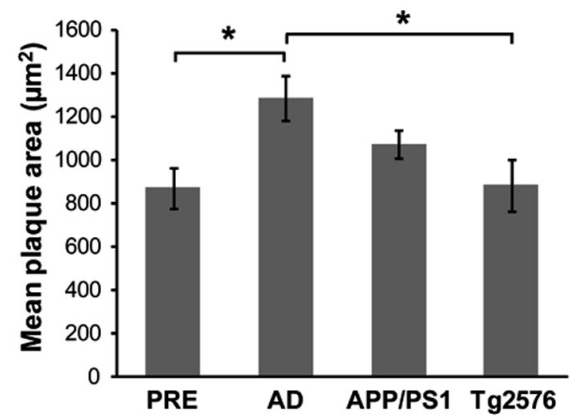

FIGURE 6 |The number of $\mathrm{NF}^{+}$, but not $\mathrm{CR}^{+}$, dystrophic neurites (DN) was significantly related to $A \beta$ plaque size in both preclinical $(A$, ${ }^{* *} p<0.001, t$-test) and end-stage AD $\left(B,{ }^{* *} p<0.001\right)$, as well as in APP/PS1 (C, $\left.{ }^{* *} p<0.001\right)$ and Tg2576 (D, ${ }^{*} p<0.01, t$-test) transgenic

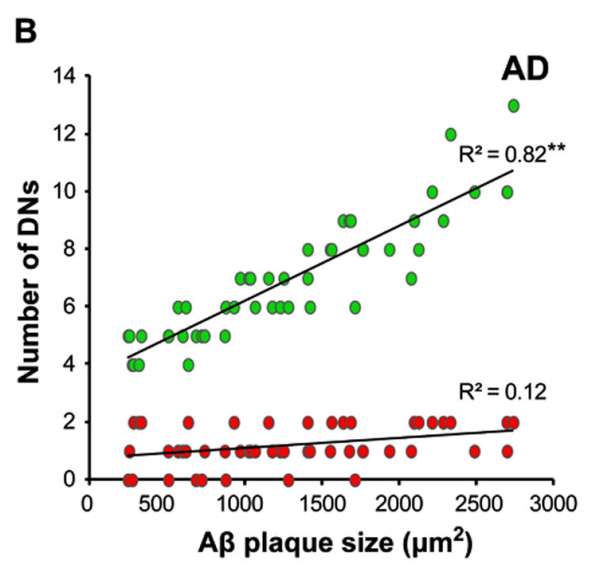

D

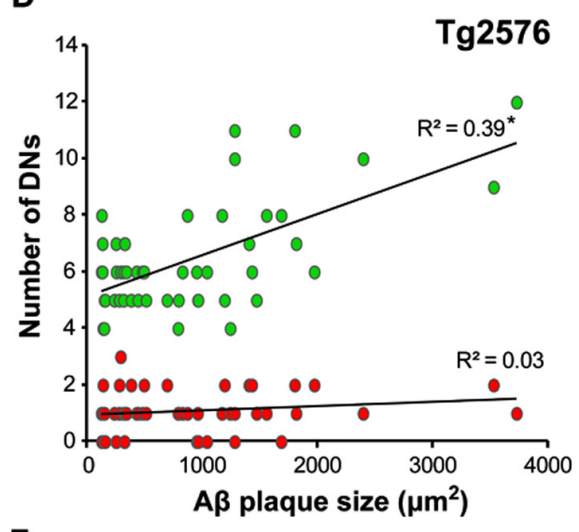

F

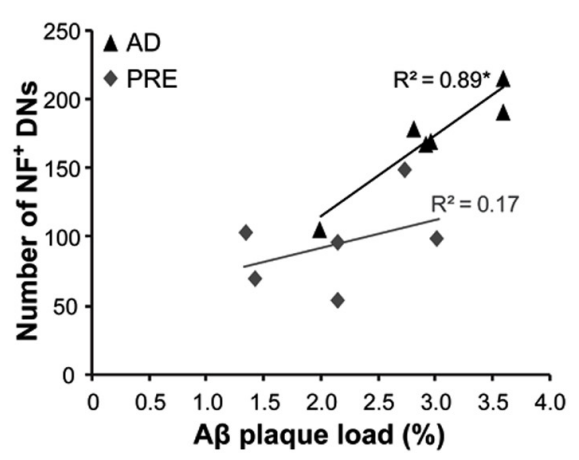

mice. End-stage $A D$ cases had the largest mean $A \beta$ plaque size $\left(\mathbf{E}^{*}{ }^{*} p<0.05\right.$, $t$-test). (F) The total number of $\mathrm{NF}^{+} \mathrm{DNs}$ per case correlated significantly with total $A \beta$ plaque load in end-stage $A D$ cases but not with preclinical cases ( $n=6$ each; ${ }^{*} p<0.01, t$-test). Error bars denote standard error of the mean. to developing extensive NFT pathology (Bussiere et al., 2003; Thangavel et al., 2009), as they accumulate large amounts of hyperphosphorylated NFs in their perikarya and axons and eventually degenerate (Morrison et al., 1987; Vickers et al., 1992, 2009; Masliah et al., 1993; Mann, 1996; Su et al., 1996; Dickson et al., 1999; Woodhouse et al., 2009b). However, overt cell death occurs mostly in end-stage $\mathrm{AD}$, and is absent in many transgenic $\mathrm{AD}$ models, suggesting that cognitive symptoms which manifest years earlier are due to neuronal dysfunction rather than loss; synaptic and axonal changes may be the earliest functional disruption. Thus, we investigated if $\mathrm{NF}^{+}$neurons were more susceptible to $\mathrm{DN}$ formation at early and end-stages of $\mathrm{AD}$, as well as in APP/PS1 and Tg2576 transgenic mice.

Studies in transgenic AD models have previously shown losses in dendritic spine density, increases in neurite curvature, sprouting, and varicosities in pyramidal neuron dendrites (Knowles et al., 1999; Le et al., 2001; Adlard and Vickers, 2002; Spires et al., 2005), as well as axonal disruption (Su et al., 1998; Adalbert et al., 2009; 
Mitew et al., 2010) associated with $A \beta$ plaques. Likewise, in the current study, we observed a progression of dystrophic changes in $\mathrm{NF}^{+}$neurites from early to end-stage human $\mathrm{AD}$, paralleled in both APP/PS1 and Tg2576 transgenic mice lines. There was an increase in the proportion of dystrophic $\mathrm{NF}^{+}$neurites across all three case types, most prominently at the plaque periphery, then the surrounding neuropil and the plaque core, respectively (Figure 2). Concomitantly, the total neurite number relative to age-matched controls decreased markedly, due to depletion in the plaque core and edge (Figure 5). This agrees with previous work showing reduced axonal density and total length in AD plaque-associated neuropil (DeWitt and Silver, 1996). The most severe changes occurred in end-stage $\mathrm{AD}$, followed by the Tg2576 and APP/PS1 mouse models, and the least severe in preclinical human $\mathrm{AD}$. The finding that $\mathrm{A} \beta$ plaques damage neurites some distance away (i.e., plaque periphery) also concurs with previous studies (Knowles et al., 1999; Le et al., 2001); retrograde swellings in axons have been reported several hundred microns from plaques in vivo (Vickers et al., 1996; Adalbert et al., 2009). This implies that dystrophic changes propagate along neurites, or that plaques possess a "halo" of toxicity that extends more distally (Koffie et al., 2009).

In contrast, $\mathrm{CR}^{+}$neurites were less dystrophic in all three plaque zones examined, with significantly more normal-appearing $\mathrm{CR}^{+}$neurites at the edge and in the periphery, but fewer total neurites (normal + dystrophic) in plaque cores. Unlike $\mathrm{NF}^{+}$neurites, which tended to traverse plaque cores, often showing signs of dystrophy, $\mathrm{CR}^{+}$neurites appeared to either terminate at the plaque periphery, or much more commonly, to elaborate around it (Figure 4). Furthermore, unlike $\mathrm{NF}^{+} \mathrm{DNs}$, counts of $\mathrm{CR}^{+} \mathrm{DNs}$ did not correlate with plaque size (Figure 6). In addition to their potential focal toxicity, larger plaques may physically distort the surrounding neuropil and cause structural alterations to neurites like increased curvature (Knowles et al., 1999; Woodhouse et al., 2005; Meyer-Luehmann et al., 2008). Therefore, $\mathrm{CR}^{+}$neurites may be more resistant to physical damage, or may have a higher capacity for structural remodeling and regeneration. We have recently shown that they exhibit greater structural plasticity than $\mathrm{GFP}^{+}$ pyramidal neurons near focal neocortical injury, rearranging their dendritic processes away from the injury site toward unaffected

\section{REFERENCES}

Adalbert, R., Nogradi, A., Babetto, E., Janeckova, L., Walker, S. A., Kerschensteiner, M., etal. (2009). Severely dystrophic axons at amyloid plaques remain continuous and connected to viable cell bodies. Brain 132 , 402-416. doi: 10.1093/brain/awn312 Adlard, P. A., and Vickers, J. C. (2002). Morphologically distinct plaque types differentially affect dendritic structure and organisation in the early and late stages of Alzheimer's disease. Acta Neuropathol. 103, 377-383. doi: 10.1007/s00401001-0476-6

Benzing, W. C., Brady, D. R., Mufson, E. J., and Armstrong, D. M. (1993). Evidence that transmitter-containing

neuropil (Blizzard et al., 2011). Likewise, in vivo imaging of adult murine cortex shows that unlike pyramidal neurons, inhibitory neurons frequently extend new dendrites and remodel existing branches (Lee et al., 2008). The results of the present study suggest that fewer $\mathrm{CR}^{+}$neurites traverse plaque cores, while many elaborate processes around plaques (Figure 4), potentially indicating dynamic restructuring away from these localized sites of neuropil injury, as previously described (Blizzard et al., 2011).

It is not clear why $\mathrm{NF}^{+}$neurons are selectively vulnerable to $\mathrm{AD}$ pathology. One possibility is that elevated $\mathrm{A} \beta$ levels interfere with normal NF regulation and transport. Indeed, increased levels of phosphorylation, either at endogenous or at novel NF phosphorylation sites (Liao et al., 2004), are a relatively early event in the pathogenesis of human AD (Wang et al., 2001; Rudrabhatla et al., 2010) and transgenic models (Vickers et al., 1994; Yang et al., 2009). Such aberrant hyperphosphorylation of NFs in AD is likely mediated by abnormal hyperactivity of kinases such as Erk1 and 2 (Veeranna et al., 2004), Cdk5 (Shea et al., 2004), and GSK3 $\beta$ (Chen et al., 2005), or the decreased activity of phosphatases such as PP2A and 1 (Rudrabhatla et al., 2009). As phosphorylation mediates many aspects of NF function including axonal transport of NFs and radial growth of axons, dysregulation of this system could critically impact cytoskeletal integrity in $\mathrm{AD}$ (Shea and Chan, 2008). Higher NF expression and phosphorylation is also associated with maturation of neurons resulting in larger axonal caliber and myelination, effectively increasing structural stability at the expense of plasticity. Therefore, a combination of lower capacity for structural remodeling and a perturbed phosphorylation balance could prime $\mathrm{NF}^{+}$neurites for DN formation and cytoskeletal dysfunction in AD.

In conclusion, we report that $\mathrm{CR}^{+}$interneurons are less susceptible than $\mathrm{NF}^{+}$neurons to neurite damage mediated by $\mathrm{A} \beta$ plaques, in both human $\mathrm{AD}$ cases and transgenic mouse models. It is likely that a combination of factors, such as a higher capacity for structural remodeling and regeneration following focal injury, contribute to this relative resistance. This study contributes to previous work showing that NFs may predispose the subpopulations of neurons that express them to structural damage in $\mathrm{AD}$ (Hof and Morrison, 1990; Hof et al., 1990, 1993; Vickers et al., 1996, 2009; Sampson et al., 1997).

induces wound healing accompanied by axonal sprouting and dendritic structural plasticity. Cereb. Cortex 21, 281-291. doi: 10.1093/cercor/ bhq091

Braak, H., and Braak, E. (1991). Neuropathological staging of Alzheimerrelated changes. Acta Neuropathol. 82, 239-259. doi: 10.1007/BF00308809

Braak, H., Thal, D. R., Ghebremedhin, E., and Del Tredici, K. (2011). Stages of the pathologic process in Alzheimer disease: age categories from 1 to 100 years. J. Neuropathol. Exp. Neurol. 70, 960-969. doi: 10.1097/NEN.0b013e318232a379

Bussiere, T., Giannakopoulos, P., Bouras, C., Perl, D. P., Morrison, J. H., and Hof, P. R. (2003). Progressive degeneration of nonphosphorylated neurofilament protein-enriched pyramidal neurons predicts cognitive impairment in Alzheimer's disease: stereologic analysis of prefrontal cortex area 9. J. Comp. Neurol. 463, 281-302. doi: 10.1002/cne. 10760

Chen, J., Zhou, J., Feng, Y., and Wang, J. (2005). Effect of GSK-3 overactivation on neurofilament phosphorylation. J. Huazhong Univ. Sci. Technol. Med. Sci. 25, 375-377, 403. doi: 10.1007/BF02828200

del Rio, M. R., and DeFelipe, J. (1997). Synaptic connections of calretinin-immunoreactive neurons in the human neocortex. J. Neurosci. 17, 5143-5154. 
DeWitt, D. A., and Silver, J. (1996). Regenerative failure: a potential mechanism for neuritic dystrophy in Alzheimer's disease. Exp. Neurol. 142, 103-110. doi: 10.1006/exnr.1996.0182

Dickson, T. C., Chuckowree, J. A., Chuah, M. I., West, A. K., and Vickers, J. C. (2005). alphaInternexin immunoreactivity reflects variable neuronal vulnerability in Alzheimer's disease and supports the role of the beta-amyloid plaques in inducing neuronal injury. Neurobiol. Dis. 18, 286-295. doi: 10.1016/j.nbd.2004.10.001

Dickson, T. C., King, C. E., Mccormack, G. H., and Vickers, J. C. (1999). Neurochemical diversity of dystrophic neurites in the early and late stages of Alzheimer's disease. Exp. Neurol. 156, 100-110. doi: 10.1006/exnr.1998.7010

Fonseca, M., and Soriano, E. (1995). Calretinin-immunoreactive neurons in the normal human temporal cortex and in Alzheimer's disease. Brain Res. 691, 83-91. doi: 10.1016/00068993(95)00622-W

Franklin, K. B. J., and Paxinos, G. (2008). The Mouse Brain in Stereotaxic Coordinates. New York, NY: Academic Press.

Hof, P. R., Cox, K., and Morrison, J. H. (1990). Quantitative analysis of a vulnerable subset of pyramidal neurons in Alzheimer's disease: I. Superior frontal and inferior temporal cortex. J. Comp. Neurol. 301, 44-54. doi: 10.1002/cne.903010105

Hof, P. R., Cox, K., Young, W. G., Celio, M. R., Rogers, J., and Morrison, J. H. (1991). Parvalbuminimmunoreactive neurons in the neocortex are resistant to degeneration in Alzheimer's disease. J. Neuropathol. Exp. Neurol. 50, 451-462. doi: 10.1097/00005072-19910700000006

Hof, P. R., and Morrison, J. H. (1990). Quantitative analysis of a vulnerable subset of pyramidal neurons in Alzheimer's disease: II. Primary and secondary visual cortex. J. Comp. Neurol. 301, 55-64. doi: 10.1002/cne.903010106

Hof, P. R., Nimchinsky, E. A., Celio, M. R., Bouras, C., and Morrison, J. H. (1993). Calretinin-immunoreactive neocortical interneurons are unaffected in Alzheimer's disease. Neurosci. Lett. 152, 145-148. doi: 10.1016/0304-3940(93)90504-E

Hof, P. R., Nimchinsky, E. A., and Morrison, J. H. (1995). Neurochemical phenotype of corticocortical connections in the macaque monkey: quantitative analysis of a subset of neurofilament protein-immunoreactive projection neurons in frontal, parietal, temporal, and cingulate cortices. J. Comp. Neurol. 362, 109-133. doi: 10.1002/cne.903620107

Hsiao, K., Chapman, P., Nilsen, S., Eckman, C., Harigaya, Y., Younkin, S., et al. (1996). Correlative memory deficits, Abeta elevation, and amyloid plaques in transgenic mice. Science 274, 99-102. doi: 10.1126/science. 274.5284 .99

Jankowsky, J. L., Fadale, D. J., Anderson, J., Xu, G. M., Gonzales, V., Jenkins, N. A., et al. (2004). Mutant presenilins specifically elevate the levels of the 42 residue beta-amyloid peptide in vivo: evidence for augmentation of a 42-specific gamma secretase. Hum. Mol. Genet. 13, 159-170. doi: 10.1093/hmg/ddh019

Kirkcaldie, M. T., Dickson, T. C., King, C. E., Grasby, D., Riederer, B. M., and Vickers, J. C. (2002). Neurofilament triplet proteins are restricted to a subset of neurons in the rat neocortex. $J$. Chem. Neuroanat. 24, 163-171. doi: 10.1016/S0891-0618(02)00043-1

Knowles, R. B., Wyart, C., Buldyrev, S. V., Cruz, L., Urbanc, B., Hasselmo, M. E., et al. (1999). Plaque-induced neurite abnormalities: implications for disruption of neural networks in Alzheimer's disease. Proc. Natl. Acad. Sci. U.S.A. 96, 5274-5279. doi: 10.1073/pnas.96.9.5274

Koffie, R. M., Meyer-Luehmann, M., Hashimoto, T., Adams, K. W., Mielke, M. L., Garcia-Alloza, M., et al. (2009). Oligomeric amyloid beta associates with postsynaptic densities and correlates with excitatory synapse loss near senile plaques. Proc. Natl. Acad. Sci. U.S.A. 106, 4012-4017. doi: 10.1073/pnas.0811698106

Le, R., Cruz, L., Urbanc, B., Knowles, R. B., Hsiao-Ashe, K., Duff, K., et al. (2001). Plaque-induced abnormalities in neurite geometry in transgenic models of Alzheimer disease: implications for neural system disruption. J. Neuropathol. Exp. Neurol. 60, $753-$ 758.

Lee, W. C., Chen, J. L., Huang, H., Leslie, J. H., Amitai, Y., So, P. T., etal. (2008). A dynamic zone defines interneuron remodeling in the adult neocortex. Proc. Natl. Acad. Sci. U.S.A. 105, 19968-19973. doi: 10.1073/pnas.0810149105

Leuba, G., Kraftsik, R., and Saini, K. (1998). Quantitative distribution of parvalbumin, calretinin, and calbindin D-28k immunoreactive neurons in the visual cortex of normal and Alzheimer cases. Exp. Neurol. 152, 278-291. doi: 10.1006/exnr.1998.6838
Lewis, D. A., Campbell, M. J., Terry, R. D., and Morrison, J. H. (1987). Laminar and regional distributions of neurofibrillary tangles and neuritic plaques in Alzheimer's disease: a quantitative study of visual and auditory cortices. J. Neurosci. 7, 17991808.

Liao, L., Cheng, D., Wang, J., Duong, D. M., Losik, T. G., Gearing, M., et al. (2004). Proteomic characterization of postmortem amyloid plaques isolated by laser capture microdissection. J. Biol. Chem. 279, 3706137068. doi: 10.1074/jbc.M403672200

Mann, D. M. (1996). Pyramidal nerve cell loss in Alzheimer's disease. Neurodegeneration 5, 423-427. doi: 10.1006/neur.1996.0057

Masliah, E., Mallory, M., Hansen, L., Alford, M., Deteresa, R., and Terry, R. (1993). An antibody against phosphorylated neurofilaments identifies a subset of damaged association axons in Alzheimer's disease. Am. J. Pathol. 142, 871-882.

Meyer-Luehmann, M., Spires-Jones, T. L., Prada, C., Garcia-Alloza, M., de Calignon, A., Rozkalne, A., et al. (2008). Rapid appearance and local toxicity of amyloid-beta plaques in a mouse model of Alzheimer's disease. Nature 451, 720-724. doi: 10.1038/nature06616

Mitew, S., Kirkcaldie, M. T., Halliday, G. M., Shepherd, C. E., Vickers, J. C., and Dickson, T. C. (2010). Focal demyelination in Alzheimer's disease and transgenic mouse models. Acta Neuropathol. 119, 567-577. doi: 10.1007/s00401-010-0657-2

Morrison, J. H., Lewis, D. A., Campbell, M. J., Huntley, G. W., Benson, D. L., and Bouras, C. (1987). A monoclonal antibody to nonphosphorylated neurofilament protein marks the vulnerable cortical neurons in Alzheimer's disease. Brain Res. 416,331-336. doi: 10.1016/00068993(87)90914-0

Park, H. J., Kong, J. H., Kang, Y. S., Park, W. M., Jeong, S. A., Park, S. M., et al. (2002). The distribution and morphology of calbindin D28Kand calretinin-immunoreactive neurons in the visual cortex of mouse. Mol. Cells 14, 143-149.

Paulussen, M., Jacobs, S., Van Der Gucht, E., Hof, P. R., and Arckens, L. (2011). Cytoarchitecture of the mouse neocortex revealed by the low-molecular-weight neurofilament protein subunit. Brain Struct. Funct. 216, 183-199. doi: 10.1007/s00429011-0311-3

Price, J. L., Mckeel, D. W. Jr., Buckles, V. D., Roe, C. M. Xiong, C., Grundman, M., et al.
(2009). Neuropathology of nondemented aging: presumptive evidence for preclinical Alzheimer disease. Neurobiol. Aging 30, 1026-1036. doi: $10.1016 /$ j.neurobiolaging.2009. 04.002

Rudrabhatla, P., Albers, W., and Pant, H. C. (2009). Peptidyl-prolyl isomerase 1 regulates protein phosphatase 2A-mediated topographic phosphorylation of neurofilament proteins. J. Neurosci. 29, 14869-14880. doi: 10.1523/JNEUROSCI.4469-09. 2009

Rudrabhatla, P., Grant, P., Jaffe, H., Strong, M. J., and Pant, H. C. (2010). Quantitative phosphoproteomic analysis of neuronal intermediate filament proteins (NF-M/H) in Alzheimer's disease by iTRAQ. FASEB J. 24, 4396-4407. doi: 10.1096/fj.10157859

Sampson, V. L., Morrison, J. H., and Vickers, J. C. (1997). The cellular basis for the relative resistance of parvalbumin and calretinin immunoreactive neocortical neurons to the pathology of Alzheimer's disease. Exp. Neurol. 145, 295-302. doi: 10.1006/exnr.1997.6433

Shea, T. B., and Chan, W. K. (2008). Regulation of neurofilament dynamics by phosphorylation. Eur. J. Neurosci. 27, 1893-1901. doi: 10.1111/j.14609568.2008.06165.x

Shea, T. B., Zheng, Y. L., Ortiz, D., and Pant, H. C. (2004). Cyclin-dependent kinase 5 increases perikaryal neurofilament phosphorylation and inhibits neurofilament axonal transport in response to oxidative stress. $J$. Neurosci. Res. 76, 795-800. doi: 10.1002/jnr.20099

Spires, T. L., Meyer-Luehmann, M., Stern, E. A., McLean, P. J., Skoch, J., Nguyen, P. T., et al. (2005). Dendritic spine abnormalities in amyloid precursor protein transgenic mice demonstrated by gene transfer and intravital multiphoton microscopy. J. Neurosci. 25, 7278-7287. doi: 10.1523/JNEUROSCI.1879-05.2005

Su, J. H., Cummings, B. J., and Cotman, C. W. (1996). Plaque biogenesis in brain aging and Alzheimer's disease. I. Progressive changes in phosphorylation states of paired helical filaments and neurofilaments. Brain Res. 739, 79-87. doi: 10.1016/S00068993(96)00811-6

$\mathrm{Su}$, J. H., Cummings, B. J., and Cotman, C. W. (1998). Plaque biogenesis in brain aging and Alzheimer's disease. II. Progressive transformation and developmental sequence of dystrophic neurites. Acta Neuropathol. 96, 463-471. doi: $10.1007 / \mathrm{s} 004010050920$ 
Szaro, B. G., and Strong, M. J. (2010). Post-transcriptional control of neurofilaments: new roles in development, regeneration and neurodegenerative disease. Trends $\mathrm{Neu}$ rosci. 33, 27-37. doi: 10.1016/j. tins.2009.10.002

Thangavel, R., Sahu, S. K., Van Hoesen, G. W., and Zaheer, A. (2009). Loss of nonphosphorylated neurofilament immunoreactivity in temporal cortical areas in Alzheimer's disease. Neuroscience 160, 427-433. doi: 10.1016/j.neuroscience.2009. 02.037

Van der Gucht, E., Hof, P. R., Van Brussel, L., Burnat, K., and Arckens, L. (2007). Neurofilament protein and neuronal activity markers define regional architectonic parcellation in the mouse visual cortex. Cereb. Cortex 17, 2805-2819. doi: 10.1093/cercor/bhm012

Veeranna, T. K., Boland, B., Odrljin, T., Mohan, P., Basavarajappa, B. S., Peterhoff, C., et al. (2004). Calpain mediates calcium-induced activation of the erk1,2 MAPK pathway and cytoskeletal phosphorylation in neurons: relevance to Alzheimer's disease. Am. J. Pathol. 165, 795805. doi: 10.1016/S0002-9440(10) 63342-1

Vickers, J. C., Chin, D., Edwards, A. M., Sampson, V., Harper, C., and Morrison, J. (1996). Dystrophic neurite formation associated with age-related beta amyloid deposition in the neocortex: clues to the genesis of neurofibrillary pathology. Exp. Neurol. 141, 1-11. doi: 10.1006/exnr.1996.0133

Vickers, J. C., and Costa, M. (1992). The neurofilament triplet is present in distinct subpopulations of neurons in the central nervous system of the guinea-pig. Neuroscience 49, 73-100. doi: 10.1016/0306-4522(92) 90077-F

Vickers, J. C., Delacourte, A., and Morrison, J. H. (1992). Progressive transformation of the cytoskeleton associated with normal aging and Alzheimer's disease. Brain Res. 594, 273278. doi: 10.1016/0006-8993(92) 91134-Z

Vickers, J. C., King, A. E., Woodhouse, A., Kirkcaldie, M. T., Staal, J. A., McCormack, G. H., et al. (2009). Axonopathy and cytoskeletal disruption in degenerative diseases of the central nervous system. Brain Res. Bull. 80, $217-$ 223. doi: 10.1016/j.brainresbull.2009. 08.004

Vickers, J. C., Morrison, J. H., Friedrich, V. L. Jr., Elder, G. A., Perl, D. P., Katz, R. N., et al. (1994). Ageassociated and cell-type-specific neurofibrillary pathology in transgenic mice expressing the human midsized neurofilament subunit. J. Neurosci. $14,5603-5612$.
Wang, J., Tung, Y. C., Wang, Y., Li, X. T., Iqbal, K., and Grundke-Iqbal, I. (2001). Hyperphosphorylation and accumulation of neurofilament proteins in Alzheimer disease brain and in okadaic acid-treated SY5Y cells. FEBS Lett. 507, 8187. doi: 10.1016/S0014-5793(01) 02944-1

Woodhouse, A., Shepherd, C. E., Sokolova, A., Carroll, V. L., King, A. E., Halliday, G. M., et al. (2009a). Cytoskeletal alterations differentiate presenilin-1 and sporadic Alzheimer's disease. Acta Neuropathol. 117, 19-29. doi: 10.1007/ s00401-008-0458-Z

Woodhouse, A., Vickers, J. C., Adlard, P. A., and Dickson, T. C. (2009b). Dystrophic neurites in TgCRND8 and Tg2576 mice mimic human pathological brain aging. Neurobiol. Aging 30, 864-874. doi: 10.1016/j.neurobiolaging.2007. 09.003

Woodhouse, A., West, A. K., Chuckowree, J. A., Vickers, J. C., and Dickson, T. C. (2005). Does betaamyloid plaque formation cause structural injury to neuronal processes? Neurotox. Res. 7, 5-15. doi: 10.1007/BF03033772

Yang, X., Yang, Y., Luo, Y., Li, G., Wang, J., and Yang, E. S. (2009). Hyperphosphorylation and accumulation of neurofilament proteins in transgenic mice with Alzheimer presenilin
1 mutation. Cell. Mol. Neurobiol. 29, 497-501. doi: 10.1007/s10571-0089341-7

Conflict of Interest Statement: The authors declare that the research was conducted in the absence of any commercial or financial relationships that could be construed as a potential conflict of interest.

Received: 07 August 2013; accepted: 08 September 2013; published online: 26 September 2013.

Citation: Mitew S, Kirkcaldie MTK, Dickson TC and Vickers JC (2013) Neu rites containing the neurofilament-triplet proteins are selectively vulnerable to cytoskeletal pathology in Alzheimer's disease and transgenic mouse models. Front. Neuroanat. 7:30. doi: 10.3389/fnana. 2013.00030

This article was submitted to the journal Frontiers in Neuroanatomy.

Copyright (c) 2013 Mitew, Kirkcaldie, Dickson and Vickers. This is an openaccess article distributed under the terms of the Creative Commons Attribution License (CC BY). The use, distribution or reproduction in other forums is permitted, provided the original author(s) or licensor are credited and that the original publication in this journal is cited, in accordance with accepted academic practice. No use, distribution or reproduction is permitted which does not comply with these terms. 